\title{
DNA Damage, an Innocent Bystander in Atrial Fibrillation and Other Cardiovascular Diseases?
}

\author{
Kennedy S. Ramos ${ }^{1,2 \star}$ and Bianca J. J. M. Brundel ${ }^{1}$ \\ 1 Department of Physiology, Amsterdam UMC, Vrije Universiteit, Amsterdam Cardiovascular Sciences, Amsterdam, \\ Netherlands, ${ }^{2}$ Department of Cardiology, Erasmus Medical Center, Rotterdam, Netherlands
}

OPEN ACCESS

Edited by:

Georges Nemer,

American University of

Beirut, Lebanon

Reviewed by:

Alexander Maass,

University Medical Center

Groningen, Netherlands

Jun Yoshioka,

CUNY School of Medicine,

United States

${ }^{*}$ Correspondence:

Kennedy S. Ramos

k.silvaramos@amsterdamumc.n

Specialty section:

This article was submitted to Cardiovascular Genetics and Systems

Medicine,

a section of the journal

Frontiers in Cardiovascular Medicine

Received: 14 February 2020

Accepted: 07 April 2020

Published: 28 April 2020

Citation:

Ramos KS and Brundel BJJM (2020) DNA Damage, an Innocent Bystander

in Atrial Fibrillation and Other

Cardiovascular Diseases?

Front. Cardiovasc. Med. 7:67.

doi: 10.3389/fcvm.2020.00067
Atrial Fibrillation (AF) is the most common clinical tachyarrhythmia with a strong tendency to progress in time. AF is difficult to treat and therefore there is a great need to dissect root causes of AF with the ultimate goal to develop mechanism-based (drug) therapies. New findings related to mechanisms driving AF progression indicate a prime role for DNA damage-induced metabolic remodeling. A recent study uncovered that AF results in oxidative DNA damage and consequently excessive poly-ADP-ribose polymerase 1 (PARP1) activation and nicotinamide adenine dinucleotide $\left(\mathrm{NAD}^{+}\right)$depletion and finally atrial cardiomyocyte electrical and contractile dysfunction. This newly elucidated role of DNA damage in AF opens opportunities for novel therapeutic strategies. Recently developed PARP inhibitors, such as ABT-888 and olaparib, provide beneficial effects in limiting experimental $A F$, and are also found to limit atherosclerotic coronary artery disease and heart failure. Another therapeutic option to protect against AF is to replenish the $\mathrm{NAD}^{+}$pool by supplementation with $\mathrm{NAD}^{+}$or its precursors, such as nicotinamide and nicotinamide riboside. In this review, we describe the role of DNA damage-mediated metabolic remodeling in AF and other cardiovascular diseases, discuss novel druggable targets for $A F$ and highlight future directions for clinical trials with drugs directed at PARP1-NAD ${ }^{+}$pathway with the ultimate aim to preserve quality of life and to attenuate severe complications such as heart failure or stroke in patients with AF.

Keywords: PARP, DNA damage, atrial fibrillation, peripartum cardiomyopathy, dilated cardiomyopathy, metabolism, lamin a/c, atrial cardiomyopathy

\section{STATE OF THE ART: AF HEALTHCARE PROBLEM}

AF is the most common progressive cardiac rhythm disorder affecting $2-3 \%$ of the Western population (1). In addition, AF is associated with serious complications such as stroke, heart failure and increased mortality (1). Compared to age-matched males, women have a higher risk of AF-related complications, including mortality and stroke (2), probably related to higher prevalence of specific risk factors including hypertension, obesity, electrophysiological differences, and absence of cardioprotective estrogens after menopause (3).

Well-known environmentally-induced risk factors associated with AF include aging and other cardiovascular diseases, including coronary artery disease, and acquired valvular heart diseases. These degenerative pathologies clustered within "wear-and-tear" program present predominance among elderly population (4). On the other hand, in up to $20 \%$ of AF patients, AF develops at a young ageand in the absence of "wear-and-tear" risk factors and gross structural heart changes 
$(5,6)$. Here, AF may be related to a genetic mutation. AF families have been identified carrying mutations in cytoskeletal proteins, including lamin A/C (LMNA) (7) and desmin (8), which have been associated with dilated (DCM) and peripartum cardiomyopathy (PPCM) onset (9).

At present, treatment modalities for AF are only moderately effective and do not prevent $\mathrm{AF}$ progression from recurrent intermittent episodes (paroxysmal) to persistent and finally permanent AF. Although invasive ablation therapy is promising in early stage AF, up to $60 \%$ of persistent AF patients show AF recurrence within 1 year and require multiple, expensive procedures (10). Pharmacological therapy of AF, which originates from the 1960s and is directed at inhibition of ion-channels, does not prevent AF progression in $85 \%$ of patients and its usage is limited by potentially severe and life-threatening side-effects (11). The response of an individual patient to pharmacological therapy can often not be predicted and selection is therefore based on "trial-and-error". Due to the lack of effective treatment modalities for AF, AF progresses in time and hence has a significant physical, psychological, societal, and economic impact. Therefore, there is an urgent unmet need to develop new (pharmaco)-therapeutic strategies directed at inhibition of mechanistic root causes of AF.

Recently published findings reveal important evidence for AF promotion due to dysmorphic nuclei-associated DNA damage, and subsequent activation of the DNA repair protein polyADP-ribose polymerase (PARP), especially PARP1. In turn, PARP1 activation results in the depletion of $\mathrm{NAD}^{+}$levels in mitochondria, which causes oxidative stress, additional DNA damage, energy depletion and AF progression (12). In this article, we review the current understanding of DNA damagePARP1-NAD ${ }^{+}$axis in the pathogenesis of AF and cardiovascular diseases. Furthermore, we discuss novel druggable targets for $\mathrm{AF}$ and highlight future directions for clinical trials with drugs directed at DNA damage-PARP1-NAD ${ }^{+}$axis with the ultimate aim to preserve quality of life and to attenuate severe complications such as heart failure or stroke in patients with AF.

\section{ROLE OF PARP1 IN CONSERVING GENETIC AND FUNCTIONAL INTEGRITY OF THE CARDIOMYOCYTE}

Maintaining the correct genetic sequence is crucial for a healthy function of dividing but also for differentiated cells, such as cardiomyocytes. Due to environmentally-induced "wear-andtear" or by design (genetics), alterations in the genetic sequence are induced. These alterations include single-strand breaks (SSBs) and double-strand breaks (DSBs) (13). As a response to these potential harmful DNA breaks, a complex machinery of DNA surveillance becomes activated to recognize the DNA damage, repair the breaks, or in case of excessive DNA damage, initiate the process of cell death (14).

PARP is a superfamily of six nuclear ADP-ribosyl transferase enzymes that are activated by SSBs and DSBs, serving to recruit the DNA repair machinery by synthesis of poly-ADPribose (PAR) chains. Poly-ADP-ribosylation (PARylation) is a post-translation modification of nuclear proteins guided by PARsynthesis. PARP1, as the most abundant nuclear family member, has three different functional domains. Firstly, zinc fingers are crucial to recognize SSBs and/or DSBs in DNA and bind to them (Figure 1). In the center, the auto-modification domain permits PARylation of PARP itself (15). Finally, the catalytic domain carries the PARP signature and is responsible for transferring ADP-ribose subunits from nicotinamide adenine dinucleotide $\left(\mathrm{NAD}^{+}\right)$to PAR and onto nuclear acceptor proteins. Simultaneously to PAR polymerization, PARP1's affinity to the damaged DNA site is weakened, due to the dense negative charge and size of the new polymer (16). Hence allowing recruitment and coupling of proteins which belong to the DNA repair machinery, including the DNA base excision repair (BER) machinery. Polymer growth is limited by polyADP-ribose glycohydrolase (PARG) that removes PAR from PARP1 by cleaving ribose-ribose bonds (17), allowing PARP1 to recognize other damaged DNA loci and initiate a new signaling and reparative cycle (18). Under healthy conditions PARP1 activity is low, however upon "wear-and-tear" and genetic conditions its catalytic activity can increase from 10 to 500 -fold $(19,20)$. During excessive PARP activation high levels of PAR chains are synthesized. Hereto, $\mathrm{NAD}^{+}$is consumed by PARP up to an extent that it depletes cellular $\mathrm{NAD}^{+}$levels. $\mathrm{NAD}^{+}$is a cofactor that is central in the metabolism of cells, including cardiomyocytes. $\mathrm{NAD}^{+}$acts in redox reactions by carrying electrons from one reaction to another and as such, a reduction in mitochondrial $\mathrm{NAD}^{+}$levels is associated with diminished capacity for ATP production (21). To restore the $\mathrm{NAD}^{+}$pool, this co-enzyme is resynthesized. $\mathrm{NAD}^{+}$resynthetization is an energy consuming process as specific steps in the glycolysis to produce ATP are $\mathrm{NAD}^{+}$ dependent. As such, $\mathrm{NAD}^{+}$depletion leads to loss in overall ATP levels (22-24). This scenario of energy failure contributes to a metabolic type of cell death via PAR-induced translocation of apoptosis-inducing factor (AIF) from the mitochondria to nucleus (25).

In addition to PARP1-induced $\mathrm{NAD}^{+}$and ATP depletion, research findings also revealed that $\mathrm{NAD}^{+}$and ATP depletion results in a biochemical and physiological imbalance by excessive production of reactive oxidant species (ROS) by mitochondria. When not efficiently compensated by antioxidant reagents, endogenous ROS have a potential deleterious influence on cellular structures, including nuclear DNA and mitochondrial DNA molecules (26). An extensive body of work has recognized the importance of ROS as a mediator on DNA damage. ROS can directly cause oxidative damage on nucleotide bases (27), including bases which share peripheral loci. Consequently, oxidized bases are recognized and repaired by the BER machinery (28), particularly glycosylase mediated base excision is firstly induced. Likewise, when such a process is simultaneously demanded on damaged bases, belonging to opposite strands, the attempt of repair actually generates a DSBs (29), resulting in an enhancement of DNA damage, PARP1 activation, and $\mathrm{NAD}^{+}$depletion.

In summary, oxidative stress may cause DNA damage and therefore activates especially PARP1, resulting in $\mathrm{NAD}^{+}$ 


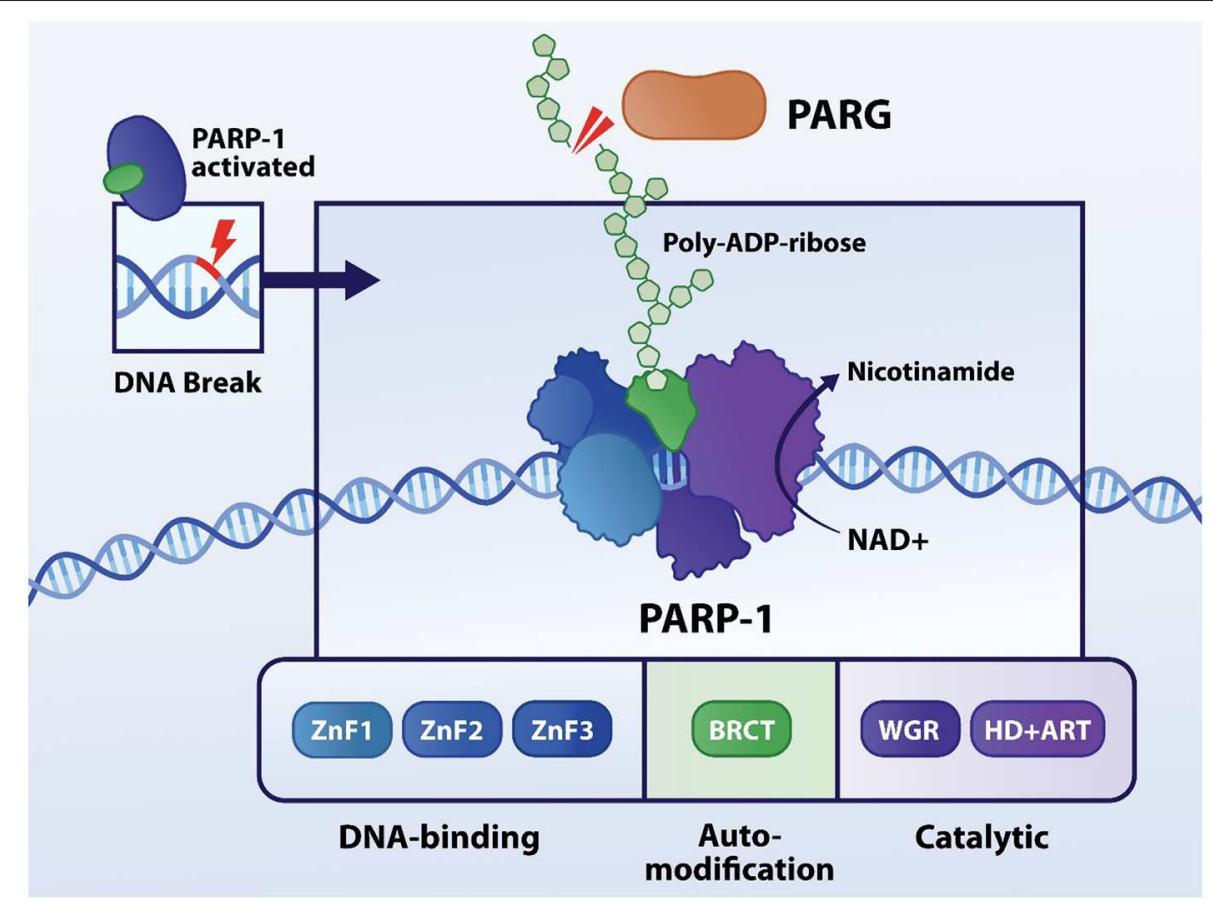

FIGURE 1 | Structure and function of PARP1. PARP1 contains three functional domains: DNA-binding, auto-modification and catalytic domain. The three zinc fingers are responsible for recognizing aberrances in DNA molecule, followed by binding to it. In the center, the auto-modification domain permits PARylation of PARP itself. Finally, the catalytic domain carries the PARP signature and is responsible for transferring ADP-ribose subunits from nicotinamide adenine dinucleotide (NAD ${ }^{+}$) to PAR onto nuclear acceptor proteins.

depletion and consequently drive further oxidative protein and DNA damage. This feed-forward mechanism is found to be associated with several cardiovascular diseases, including AF. As such, the activation of the DNA damage-PARP1-NAD ${ }^{+}$axis plays an important role in impairment of genomic integrity, mitochondria control, and ultimately result in cardiomyocyte dysfunction (19).

\section{ROLE OF DNA DAMAGE-PARP1-NAD ${ }^{+}$ AXIS IN ATRIAL FIBRILLATION}

Recently published findings reveal important evidence for the presence of dysmorphic nuclei which associate with DNA damage and increased PARP1 activation in experimental and clinical AF (12). In turn, PARP1 activation results in consumption of $\mathrm{NAD}^{+}$levels from mitochondria to such an extent, that it depletes intracellular $\mathrm{NAD}^{+}$levels, thereby exacerbating oxidative damage to proteins and DNA (Figure 2). Activation of this sequel is likely triggered by a substantial increase in myocardial energy demand resulting from the fourto six-fold increase in electrical and contractile activity during AF episodes. Subsequent failure to meet the increased energy demand results in progressive dysfunction of mitochondria, oxidative damage to proteins and DNA and has been associated with disruption of the microtubule network (Figure 2) (30). DNA damage then activates PARP1 initiating the depletion of $\mathrm{NAD}^{+}$. This feed-forward mechanism is precluded by replenishment of
$\mathrm{NAD}^{+}$levels and pharmacological inhibition of PARP1 with 3-aminobenzamide (3AB), veliparib (ABT-888), or olaparib and genetic depletion of PARP1 (30). Heat Shock Proteins (HSP) are crucial to ensure balanced protein synthesis, folding and clearance and also stabilization of the structural protein network (i.e., proteostasis) (31). This ensured proteostasis attenuates AF-induced microtubule network disruption and consequently ameliorates DNA damage-induced PARP1 activation and $\mathrm{NAD}^{+}$ depletion in atrial cardiomyocytes. Consistent with these findings, atrial cardiomyocytes of patients with persistent $\mathrm{AF}$ also show significant DNA damage, which correlates with PARP1 activity. In addition, in atrial cardiomyocytes, DNA damage was associated with electrophysiological deterioration, including prolongation of action potential duration (possibly via the reduction in potassium channel expression $(32,33)$, reduction in cardiomyocyte excitability and increased dispersion of action potential duration, thereby creating a molecular and structural substrate for further arrhythmogenesis In tachypaced atrial cardiomyocytes, PARP inhibitors prevent PARP1 activation and consequently $\mathrm{NAD}^{+}$depletion, and thereby protect against electrophysiological deterioration, and arrhytmicity (12). These findings not only indicate a novel mechanism by which AF impairs atrial cardiomyocyte function, but also indicate PARP1-inhibition, $\mathrm{NAD}^{+}$supplementation and/or microtubule conservation as a possible therapeutic target that may preserve atrial cardiomyocyte function in clinical AF. Further studies are still necessary to ensure similar results in other cardiac cell types. 


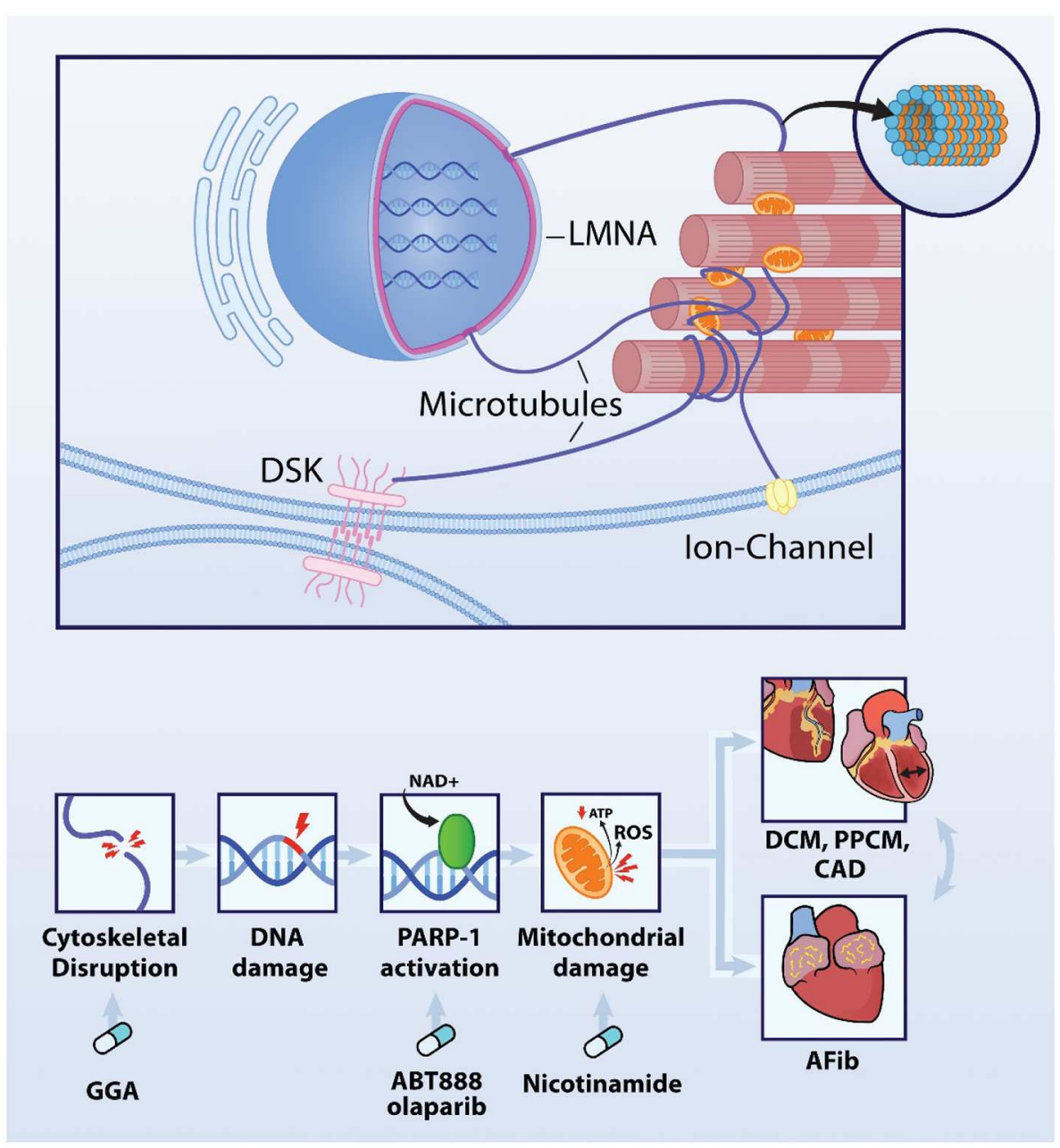

FIGURE 2 | DNA damage-PARP1-NAD+ axis is involved in AF and additional cardiovascular diseases. AF causes disruption of the microtubule network, DNA damage, PARP1 activation and excessive depletion of the NAD+ levels resulting in ATP depletion and ROS production in the mitochondria. This mechanism is driving AF, Interestingly, comparable mechanism is obverved in LMNA mutation-induced DCM and PPCM as well as atherosclerotic CAD. Importantly, AF is often associated with these cardiovascular diseases, and vice versa indicating that mechanisms driving these cardiac diseases may the enhance each other. Key modulators within this axis are druggable targets as conservation of the cytoskeletal network with the HSP-inducer geranylgeranylacetone (GGA), PARP1 inhibitors ABT-888 and olaparib and precursor of $\mathrm{NAD}^{+}$, nicotinamide protect against AF, CAD, DCM, and PPCM.

\section{ROLE OF DNA DAMAGE-PARP1-NAD ${ }^{+}$ AXIS IN CORONARY ARTERY DISEASE}

Emerging evidence indicates that hypoxia followed by reoxygenation promotes oxidative stress, release of free radicals and oxidizing species which, in turn, promote DNA damage, activate PARP by stimulating PARylation, and ultimately result in depletion of $\mathrm{NAD}^{+}$and ATP levels (Figure 2) $(34,35)$. In studies using rat and rabbit models of ischemia-reperfusion, administration of the PARP inhibitor $3 \mathrm{AB}$ resulted in an improvement in heart function, including systolic and diastolic function, and reduced the size of ischemic areas in left ventricular wall compared to non-treated control animals, who showed elevated levels of necrosis, neutrophil infiltration and reduced levels of ATP $(35,36)$. In addition, findings from hypoxiareoxygenation in vitro models of cardiomyoblasts, also revealed
PARP activation, energy loss, exuberant necrosis, and AIF dependent apoptosis. Moreover, administration of the PARP inhibitor PJ34 prevented apoptosis (34). The role of PARP as modulator of the pathway of cell death, triggered by ischemic/infarction conditions, has also been investigated in rat models. Here, administration of the PARP inhibitor PJ34 promoted a shift from an expected major necrosis, which is proinflammatory driven, toward a less harmful and programmed apoptosis process intermediated by AIF (37). In this model, initial damage is not massively avoided, instead the chronic tissue damage due to energy metabolites, exuberant inflammation and cell death induction, can be diminished toward less harmful standards $(38,39)$. Thus, the findings to date indicate that the DNA damage-PARP1-NAD ${ }^{+}$axis is also indicated in coronary artery disease and therefore may represent a novel target for therapeutic treatment. 


\section{DNA DAMAGE-PARP1-NAD ${ }^{+}$AXIS IN LMNA MUTATION-INDUCED DILATED CARDIOMYOPATHY}

Dilated cardiomyopathy (DCM) is a clinical diagnosis characterized by left or bi-ventricular enlargement which implies inefficient systolic function, and ultimately results in heart failure or sudden cardiac arrest (40). Interestingly, $40 \%$ of DCM cases rely their etiology on genetic mutations (41). Among the DCM-related mutant genes, mutations in cytoskeletal protein $L M N A$ have a high prevalence (41). Interestingly, several AF families have been identified that carry a mutation in LMNA, suggesting that this mutation also is involved in $\mathrm{AF}$ onset (7). The intermediate filament protein LMNA is linked via microtubule network with the outer cell membrane, with sarcomeric proteins such as titin, Z-disk and the nuclear membrane, and thereby regulates sarcomere architecture and function but also nuclear morphology, DNA stability and thereby gene expression (Figure 2) (42-45). Malfunction of LMNA proteins has been associated with cardiac manifestations such as compromised conduction disorders, and arrhythmogenesis, and consequently contributes to clinical phenotype compatible with DCM (46). So far, studies in ventricular cardiomyocytes revealed that LMNA mutations result in cytoskeletal and microtubule disruption (44, 47), dysmorphology of the nuclei (42), activation of the DNA damage response (48) and PARP1 activation $(49,50)$ followed by consumption of mitochondrial $\mathrm{NAD}^{+}$levels, which drive cardiomyocyte dysfunction and cardiomyopathy onset $(49,51)$. In DCM, all these effects were ameliorated by supplementation with a precursor of $\mathrm{NAD}^{+}$, nicotinamide (50), or conservation of the cytoskeletal network with GGA, a HSP-inducer (47).

Thus, the findings indicate that mutations in cytoskeletal protein LMNA result in DNA damage, PARP1 activation and $\mathrm{NAD}^{+}$depletion in ventricular cardiomyocytes. It is still not entirely understood whether the same mechanism underlies cytoskeletal protein mutation in atrial cardiomyocytes, thereby potentially inducing AF in LMNA mutation carriers.

\section{DNA DAMAGE ON PERIPARTUM CARDIOMYOPATHY}

Peripartum Cardiomyopathy (PPCM) is a dilated cardiomyopathy which manifests in the last trimester of the pregnancy, during delivery or during the first six months postpartum (52). Its diagnosis is made by exclusion criteria: when the left ventricle ejection faction is below $45 \%$, unexplained by any other underlying cardiovascular disease, during the mentioned period (53). In accordance with other cardiovascular diseases, its incidence has progressively increased over the course of recent years. Recent studies have brought the etiology of PPCM toward a multi factor syndrome, likewise several pathophysiological mechanisms may underlie PPCM induction and/or progression. PPCM in combination with $\mathrm{AF}$ accelerates disease progression and impairs recovery from PPCM, indicating AF as an enhancer of PPCM severity (54). As a major potential common pathway, excessive oxidative stress associated with impaired antioxidant

TABLE 1 | Drugs targeting DNA damage-PARP1-NAD ${ }^{+}$axis with potential benefit in AF.

\begin{tabular}{|c|c|c|c|c|c|}
\hline Key modulators & Drug & Action & Clinical phase & Indication & $\begin{array}{l}\text { Ref/identifier } \\
\text { (clinicaltrails.gov) }\end{array}$ \\
\hline \multicolumn{6}{|c|}{ I. Direct targeting DNA damage-PARP1-NAD ${ }^{+}$axis } \\
\hline DNA damage & Veliparib & PARP inhibitor & $\begin{array}{l}\text { Phase II } \\
\text { Phase II } \\
\text { Phase I } \\
\text { Phase II } \\
\text { Phase II } \\
\text { Preclinical }\end{array}$ & $\begin{array}{l}\text { Metastatic breast cancer } \\
\text { Hepatocellular carcinoma } \\
\text { Adult solid neoplasm } \\
\text { Ovarian cancer } \\
\text { Colorectal cancer } \\
\text { AF }\end{array}$ & $\begin{array}{l}\text { NCT01009788 } \\
\text { NCT01205828 } \\
\text { NCT01154426 } \\
\text { NCT01113957 } \\
\text { NCT01051596 } \\
(12)\end{array}$ \\
\hline DNA damage & Olaparib & PARP inhibitor & $\begin{array}{l}\text { Phase I } \\
\text { Phase III } \\
\text { Phase III }\end{array}$ & $\begin{array}{l}\text { Ovarian cancer } \\
\text { Pancreatic cancer } \\
\text { Fallopian Tube Clear } \\
\text { Cell Adenocarcinoma }\end{array}$ & $\begin{array}{l}\text { NCT01237067 } \\
\text { NCT02184195 } \\
\text { NCT02446600 }\end{array}$ \\
\hline $\begin{array}{l}\text { Mitochondrial } \\
\text { dysfunction }\end{array}$ & $\begin{array}{l}\text { Nicotinamide } \\
\left(\text { niagen }^{\circledR}\right)\end{array}$ & $\begin{array}{l}\text { PARP inhibitor } \\
\text { Sirt inhibitor } \\
\text { NAD-precursor }\end{array}$ & $\begin{array}{l}\text { Phase III } \\
\text { Phase III } \\
\text { Phase II } \\
\text { Phase II } \\
\text { Preclinical }\end{array}$ & $\begin{array}{l}\text { Lung carcinoma } \\
\text { Chronic kidney disease } \\
\text { Neurodegenerative disease } \\
\text { Alzheimer's disease } \\
\text { AF }\end{array}$ & $\begin{array}{l}\text { NCT02416739 } \\
\text { NCT02258074 } \\
\text { NCT01589809 } \\
\text { NCT00580931 } \\
\text { (30) }\end{array}$ \\
\hline
\end{tabular}

II. Indirect targeting conservation of cytoskeleton cardiomyocytes

\begin{tabular}{|c|c|c|c|c|c|}
\hline HSP & GGA (teprenone) & HSP induction & $\begin{array}{l}\text { Phase IV } \\
\text { Phase IV } \\
\text { Phase IV } \\
\text { Preclinical } \\
\text { Phase II }\end{array}$ & $\begin{array}{l}\text { Gastric ulcers } \\
\text { Gastritis } \\
\text { Gastric lesion } \\
\text { AF } \\
\text { Cardiac bypass surgery }\end{array}$ & $\begin{array}{l}\text { NCT01190657 } \\
\text { NCT015475559 } \\
\text { NCT01397448 } \\
(58,59)\end{array}$ \\
\hline HSP & GGA derivatives & HSP induction & Preclinical & $\mathrm{AF}$ & (60) \\
\hline
\end{tabular}


compensation seems to drive the development of PPCM phenotype (55). As part of the physiological changes during pregnancy (56), there is a higher oxidative stress, consequently enhancing ROS production. This pro-oxidative state seems to play an important role promoting DNA damage response pathway (57). Interestingly, recent research findings indicate a link between the expression of pathological gene variants of cardiomyopathy and DNA damage response pathway and PPCM. Whole exome sequencing in PPCM patients revealed that in addition to an increase in pathological cardiomyopathy gene variants, such as LMNA mutation, also an increase in gene variants affecting the DNA damage response pathway are associated with PPCM (Figure 2). These observations clearly point to a role for DNA damage pathway as key modulator in PPCM as well as LMNA mutation-induced PPCM. Future studies should reveal the exact role of DNA damage-PARP1-NAD ${ }^{+}$axis in PPCM and AF associated PPCM.

\section{INTERVENTION AT THE DNA DAMAGE-PARP1-NAD ${ }^{+}$AXIS AS A NOVEL THERAPEUTIC APPROACH OF AF}

The identification of the prime role of DNA damage$\mathrm{PARP}-\mathrm{NAD}^{+}$axis in $\mathrm{AF}$, liaises a wide variety of potential novel therapeutic approaches in AF. In order to prevent AF-induced cardiomyocyte dysfunction and potential AF progression, several targets for drug treatment that have been studied under experimental conditions, have shown promising findings and therefore may be applicable to the clinical field. These drugs include PARP inhibitors, $\mathrm{NAD}^{+}$ replenishment with nicotinamide and HSP-inducing compounds such as GGA (Table 1). An extensive body of work has been dedicated to develop optimal PARP inhibitors and to improve pharmacokinetics-dynamics, with the aim to select a drug with improved specificity, cardiac delivery and less drug-drug interaction. Even though the first PARP inhibitors were described 40 years ago (61), an exuberant increase in clinical trials has been reported recently. For example, the PARP1 inhibitor olaparib is already in phase III clinical trials for the treatment of metastatic breast cancer (62) and ABT-888 in phase I/II clinical trials for the treatment of ovarian cancers presenting BRCA mutations (Table 1). Olaparib is a favorable drug as it presents with high potency, low toxicity, and limited influence on QT/QTc interval (63). The second promising therapeutic strategy to prevent cardiomyocyte malfunction due to energetic failure is exogenous replenishment of $\mathrm{NAD}^{+}$by its precursors nicotinamide riboside and nicotinamide $(12,30)$. Nicotinamide can be converted into $\mathrm{NAD}^{+}$via the savage pathway. Also, nicotinamide acts as a PARP inhibitor claiming a synergetic dual pharmacodynamic effect. As deprivation of cardiac energy is associated with heart failure (64), mice treated with nicotinamide show amelioration in left ventricular contractile dysfunction and chamber dilatation (65), and consequently reveal attenuation of heart failure progression (49). The high translational potential and applicability in humans has been recently shown in an open-label pharmacokinetics study with nicotinamide ribose (niagen ${ }^{\circledR}$, Chromadex) in healthy subjects. Here, niagen showed good up-take tolerance (even up to $2 \mathrm{x} 1000 \mathrm{mg} /$ day) and resulted in an increase in circulating $\mathrm{NAD}^{+}$ levels (66). As AF is also associated with PARP1-induced NAD ${ }^{+}$ deprivation, replenishment of the intracellular $\mathrm{NAD}^{+}$pools with nicotinamide riboside may represent a potential novel therapy in AF. Also, HSP-inducing drugs, such as geranylgeranylacetone (GGA) and GGA derivatives, may represent interesting drugs to treat AF patients. GGA and GGA derivatives were found to attenuate tachypacing-induced electrical and contractile dysfunction by conserving the microtubule network in atrial cardiomyocyte, Drosophila and dog models for $\mathrm{AF}(58,67,68)$. HSP-inducing compounds may also attenuate DNA damageinduced PARP1 activation and $\mathrm{NAD}^{+}$depletion in $\mathrm{AF}$, as GGA was previously observed to attenuate this pathway in LMNA mutant-induced DCM (47). We are advocating for clinical studies to establish whether these marketed and mechanismbased drugs are able to reduce the burden of AF and AF-related complications such as stroke and heart failure.

\section{SUMMARY}

Atrial Fibrillation is the most common cardiac arrhythmia with a strong tendency to progress in time. Emerging evidence on mechanisms driving AF progression indicate a prime role for DNA damage-induced metabolic remodeling in atrial cardiomyocytes. This newly elucidated role of DNA damage in AF opens opportunities for novel therapeutic strategies, including PARP inhibitors, nicotinamide and nicotinamide riboside and HSP-inducing compounds. In addition, a comparable role for DNA damage has been observed in other cardiac diseases, including LMNA mutationinduced dilated cardiomyopathy, peripartum cardiomyopathy and coronary artery disease. This observation indicates a bidirectional influence between $\mathrm{AF}$ and these other cardiovascular diseases, linked by a general DNA damageinduced metabolic remodeling pathway. As such the DNA damage-induced metabolic remodeling pathway underlies atrial as well as ventricular cardiomyopathy.

\section{AUTHOR CONTRIBUTIONS}

$\mathrm{KR}$ and $\mathrm{BB}$ discussed the content, drafted and finalized the manuscript, and designed the figures.

\section{FUNDING}

This work was supported by grant CVON-STW2016-14728 AFFIP and by Medical Delta.

\section{ACKNOWLEDGMENTS}

The authors thank Miles Henderson for graphic design of the figures. 


\section{REFERENCES}

1. Zoni-Berisso M, Lercari F, Carazza T, Domenicucci S. Epidemiology of atrial fibrillation: European perspective. Clin Epidemiol. (2014) 6:213-20. doi: $10.2147 /$ CLEP.S47385

2. Heemstra HE, Nieuwlaat R, Meijboom M, Crijns HJ. The burden of atrial fibrillation in the Netherlands. Neth Heart J. (2011) 19:373-8. doi: 10.1007/s12471-011-0175-4

3. Andrade JG, Deyell MW, Lee AYK, Macle L. Sex differences in atrial fibrillation. Can J Cardiol. (2018) 34:429-36. doi: 10.1016/j.cjca.2017.11.022

4. Iung B, Vahanian A. Epidemiology of acquired valvular heart disease. Can J Cardiol. (2014) 30:962-70. doi: 10.1016/j.cjca.2014.03.022

5. Palatinus JA, Das S. Your father and grandfather's atrial fibrillation: a review of the genetics of the most common pathologic cardiac dysrhythmia. Curr Genomics. (2015) 16:75-81. doi: 10.2174/1389202916666150108222031

6. Tucker NR, Clauss S, Ellinor PT. Common variation in atrial fibrillation: navigating the path from genetic association to mechanism. Cardiovasc Res. (2016) 109:493-501. doi: 10.1093/cvr/cvv283

7. Hoorntje ET, Bollen IA, Barge-Schaapveld DQ, van Tienen FH, Te Meerman GJ, Jansweijer JA, et al. Lamin A/C-related cardiac disease: late onset with a variable and mild phenotype in a large cohort of patients with the lamin A/C p. (Arg331Gln) founder mutation. Circ Cardiovasc Genet. (2017) 10:e1631. doi: 10.1161/CIRCGENETICS.116.001631

8. van Spaendonck-Zwarts KY, van Hessem L, Jongbloed JD, de Walle HE, Capetanaki Y, van der Kooi AJ, et al. Desmin-related myopathy. Clin Genet. (2011) 80:354-66. doi: 10.1111/j.1399-0004.2010.01512.x

9. Pfeffer TJ, Schlothauer S, Pietzsch S, Schaufelberger M, Auber B, Ricke-Hoch $\mathrm{M}$, et al. Increased cancer prevalence in peripartum cardiomyopathy. JACC Cardio Oncol. (2019) 1:196-205. doi: 10.1016/j.jaccao.2019. 09.008

10. Calkins H, Hindricks G, Cappato R, Kim YH, Saad EB, Aguinaga L, et al. HRS/EHRA/ECAS/APHRS/SOLAECE expert consensus statement on catheter and surgical ablation of atrial fibrillation: executive summary. Heart Rhythm. (2017) 14:e445-e94. doi: 10.1093/europace/eux274

11. Kirchhof P, Benussi S, Kotecha D, Ahlsson A, Atar D, Casadei B, et al. ESC Guidelines for the management of atrial fibrillation developed in collaboration with EACTS. Europace. (2016) 18:1609-78. doi: 10.5603/KP.2016.0172

12. Zhang D, Hu X, Li J, Liu J, Baks-Te Bulte L, Wiersma M, et al. DNA damageinduced PARP1 activation confers cardiomyocyte dysfunction through $\mathrm{NAD}^{+}$ depletion in experimental atrial fibrillation. Nat Commun. (2019) 10:1307. doi: 10.1038/s41467-019-09014-2

13. Chatterjee N, Walker GC. Mechanisms of DNA damage, repair, and mutagenesis. Environ Mol Mutagen. (2017) 58:235-63. doi: 10.1002/em.22087

14. Matt S, Hofmann TG. The DNA damage-induced cell death response: a roadmap to kill cancer cells. Cell Mol Life Sci. (2016) 73:2829-50. doi: 10.1007/s00018-016-2130-4

15. Tao Z, Gao P, Liu HW. Identification of the ADP-ribosylation sites in the PARP-1 automodification domain: analysis and implications. J Am Chem Soc. (2009) 131:14258-60. doi: 10.1021/ja906135d

16. Dantzer F, Ame JC, Schreiber V, Nakamura J, Menissier-de Murcia J, de Murcia G. Poly(ADP-ribose) polymerase-1 activation during DNA damage and repair. Methods Enzymol. (2006) 409:493-510. doi: 10.1016/S0076-6879(05)09029-4

17. Feng X, Koh DW. Roles of poly(ADP-ribose) glycohydrolase in DNA damage and apoptosis. Int Rev Cell Mol Biol. (2013) 304:227-81. doi: 10.1016/B978-0-12-407696-9.00005-1

18. Burkle A, Virag L. Poly(ADP-ribose): PARadigms and PARadoxes. Mol Aspects Med. (2013) 34:1046-65. doi: 10.1016/j.mam.2012.12.010

19. Hassa PO, Hottiger MO. The diverse biological roles of mammalian PARPS, a small but powerful family of poly-ADP-ribose polymerases. Front Biosci. (2008) 13:3046-82. doi: 10.2741/2909

20. Skidmore CJ, Davies MI, Goodwin PM, Halldorsson H, Lewis PJ, Shall S, et al. The involvement of poly(ADP-ribose) polymerase in the degradation of NAD caused by gamma-radiation and N-methyl-N-nitrosourea. Eur J Biochem. (1979) 101:135-42. doi: 10.1111/j.1432-1033.1979.tb04225.x

21. Chinopoulos C. Acute sources of mitochondrial $\mathrm{NAD}^{+}$during respiratory chain dysfunction. Exp Neurol. (2020) 327:113218. doi: $10.1016 /$ j.expneurol.2020.113218
22. Ying W, Garnier P, Swanson RA. NAD ${ }^{+}$repletion prevents PARP1-induced glycolytic blockade and cell death in cultured mouse astrocytes. Biochem Biophys Res Commun. (2003) 308:809-13. doi: 10.1016/S0006-291X(03)01483-9

23. Zhang J, Dawson VL, Dawson TM, Snyder SH. Nitric oxide activation of poly(ADP-ribose) synthetase in neurotoxicity. Science. (1994) 263:687-9. doi: 10.1126/science. 8080500

24. Zong WX, Ditsworth D, Bauer DE, Wang ZQ, Thompson CB. Alkylating DNA damage stimulates a regulated form of necrotic cell death. Genes Dev. (2004) 18:1272-82. doi: 10.1101/gad.1199904

25. Alano CC, Garnier P, Ying W, Higashi Y, Kauppinen TM, Swanson RA. $\mathrm{NAD}^{+}$depletion is necessary and sufficient for poly(ADP-ribose) polymerase-1-mediated neuronal death. J Neurosci. (2010) 30:2967-78. doi: 10.1523/JNEUROSCI.5552-09.2010

26. Kowaltowski AJ, de Souza-Pinto NC, Castilho RF, Vercesi AE. Mitochondria and reactive oxygen species. Free Radic Biol Med. (2009) 47:333-43. doi: 10.1016/j.freeradbiomed.2009.05.004

27. Shokolenko I, Venediktova N, Bochkareva A, Wilson GL, Alexeyev MF. Oxidative stress induces degradation of mitochondrial DNA. Nucleic Acids Res. (2009) 37:2539-48. doi: 10.1093/nar/gkp100

28. Srinivas US, Tan BWQ, Vellayappan BA, Jeyasekharan AD. ROS and the DNA damage response in cancer. Redox Biol. (2019) 25:101084. doi: 10.1016/j.redox.2018.101084

29. Cannan WJ, Tsang BP, Wallace SS, Pederson DS. Nucleosomes suppress the formation of double-strand DNA breaks during attempted base excision repair of clustered oxidative damages. J Biol Chem. (2014) 289:19881-93. doi: 10.1074/jbc.M114.571588

30. Zhang D, Wu CT, Qi X, Meijering RA, Hoogstra-Berends F, Tadevosyan A, et al. Activation of histone deacetylase-6 induces contractile dysfunction through derailment of alpha-tubulin proteostasis in experimental and human atrial fibrillation. Circulation. (2014) 129:346-58. doi: 10.1161/CIRCULATIONAHA.113.005300

31. Latchman DS. Heat shock proteins and cardiac protection. Cardiovasc Res. (2001) 51:637-46. doi: 10.1016/S0008-6363(01)00354-6

32. Brundel BJ, Van Gelder IC, Henning RH, Tieleman RG, Tuinenburg AE, Wietses $\mathrm{M}$, et al. Ion channel remodeling is related to intraoperative atrial effective refractory periods in patients with paroxysmal and persistent atrial fibrillation. Circulation. (2001) 103:684-90. doi: 10.1161/01.CIR.103.5.684

33. Brundel BJ, Van Gelder IC, Henning RH, Tuinenburg AE, Wietses M, Grandjean JG, et al. Alterations in potassium channel gene expression in atria of patients with persistent and paroxysmal atrial fibrillation: differential regulation of protein and mRNA levels for $\mathrm{K}^{+}$channels. J Am Coll Cardiol. (2001) 37:926-32. doi: 10.1016/S0735-1097(00)01195-5

34. Fiorillo C, Ponziani V, Giannini L, Cecchi C, Celli A, Nassi N, et al. Protective effects of the PARP-1 inhibitor PJ34 in hypoxicreoxygenated cardiomyoblasts. Cell Mol Life Sci. (2006) 63:3061-71. doi: 10.1007/s00018-006-6345-7

35. Thiemermann C, Bowes J, Myint FP, Vane JR. Inhibition of the activity of poly(ADP ribose) synthetase reduces ischemia-reperfusion injury in the heart and skeletal muscle. Proc Natl Acad Sci USA. (1997) 94:679-83. doi: 10.1073/pnas.94.2.679

36. Zingarelli B, Cuzzocrea S, Zsengeller Z, Salzman AL, Szabo C. Protection against myocardial ischemia and reperfusion injury by 3-aminobenzamide, an inhibitor of poly (ADP-ribose) synthetase. Cardiovasc Res. (1997) 36:205-15. doi: 10.1016/S0008-6363(97)00137-5

37. Xiao CY, Chen M, Zsengeller Z, Li H, Kiss L, Kollai M, et al. Poly(ADPRibose) polymerase promotes cardiac remodeling, contractile failure, and translocation of apoptosis-inducing factor in a murine experimental model of aortic banding and heart failure. J Pharmacol Exp Ther. (2005) 312:891-8. doi: 10.1124/jpet.104.077164

38. Pacher P, Liaudet L, Mabley J, Komjati K, Szabo C. Pharmacologic inhibition of poly(adenosine diphosphate-ribose) polymerase may represent a novel therapeutic approach in chronic heart failure. J Am Coll Cardiol. (2002) 40:1006-16. doi: 10.1016/S0735-1097(02)02062-4

39. Song ZF, Chen DY, Du B, Ji XP. Poly (ADP-ribose) polymerase inhibitor reduces heart ischaemia/reperfusion injury via inflammation and Akt signalling in rats. Chin Med J (Engl). (2013) 126:1913-7. doi: 10.3760/cma.j.issn.0366-6999.20121234 
40. Watkins $\mathrm{H}$, Ashrafian $\mathrm{H}$, Redwood C. Inherited cardiomyopathies. N Engl J Med. (2011) 364:1643-56. doi: 10.1056/NEJMra0902923

41. Hershberger RE, Hedges DJ, Morales A. Dilated cardiomyopathy: the complexity of a diverse genetic architecture. Nat Rev Cardiol. (2013) 10:53147. doi: $10.1038 /$ nrcardio. 2013.105

42. Barateau A, Vadrot N, Vicart P, Ferreiro A, Mayer M, Heron D, et al. A novel lamin a mutant responsible for congenital muscular dystrophy causes distinct abnormalities of the cell nucleus. PLoS ONE. (2017) 12:e0169189. doi: 10.1371/journal.pone.0169189

43. Henning RH, Brundel B. Proteostasis in cardiac health and disease. Nat Rev Cardiol. (2017) 14:637-53. doi: 10.1038/nrcardio.2017.89

44. Ho CY, Jaalouk DE, Vartiainen MK, Lammerding J. Lamin A/C and emerin regulate MKL1-SRF activity by modulating actin dynamics. Nature. (2013) 497:507-11. doi: 10.1038/nature12105

45. Macquart C, Juttner R, Morales Rodriguez B, Le Dour C, Lefebvre F, Chatzifrangkeskou $\mathrm{M}$, et al. Microtubule cytoskeleton regulates connexin 43 localization and cardiac conduction in cardiomyopathy caused by mutation in A-type lamins gene. Hum Mol Genet. (2019) 28:4043-52. doi: $10.1093 / \mathrm{hmg} / \mathrm{ddy} 227$

46. Lin F, Worman HJ. Structural organization of the human gene encoding nuclear lamin A and nuclear lamin C. J Biol Chem. (1993) 268:16321-6.

47. Galata Z, Kloukina I, Kostavasili I, Varela A, Davos CH, Makridakis M, et al. Amelioration of desmin network defects by $\alpha \mathrm{B}$-crystallin overexpression confers cardioprotection in a mouse model of dilated cardiomyopathy caused by LMNA gene mutation. J Mol Cell Cardiol. (2018) 125:73-86. doi: 10.1016/j.yjmcc.2018.10.017

48. Chen SN, Lombardi R, Karmouch J, Tsai JY, Czernuszewicz G, Taylor MRG, et al. DNA damage response/TP53 pathway is activated and contributes to the pathogenesis of dilated cardiomyopathy associated with LMNA (Lamin A/C) mutations. Circ Res. (2019) 124:856-73. doi: 10.1161/CIRCRESAHA.118.314238

49. Diguet N, Trammell SAJ, Tannous C, Deloux R, Piquereau J, Mougenot $\mathrm{N}$, et al. Nicotinamide riboside preserves cardiac function in a mouse model of dilated cardiomyopathy. Circulation. (2018) 137:2256-73. doi: 10.1161/CIRCULATIONAHA.116.026099

50. Vignier N, Chatzifrangkeskou M, Morales Rodriguez B, Mericskay M, Mougenot N, Wahbi K, et al. Rescue of biosynthesis of nicotinamide adenine dinucleotide protects the heart in cardiomyopathy caused by lamin A/C gene mutation. Hum Mol Genet. (2018) 27:3870-80. doi: 10.1093/hmg/ddy278

51. Murata MM, Kong X, Moncada E, Chen Y, Imamura H, Wang P, et al. NAD ${ }^{+}$ consumption by PARP1 in response to DNA damage triggers metabolic shift critical for damaged cell survival. Mol Biol Cell. (2019) 30:2584-97. doi: 10.1091/mbc.E18-10-0650

52. Hilfiker-Kleiner D, Sliwa K. Pathophysiology and epidemiology of peripartum cardiomyopathy. Nat Rev Cardiol. (2014) 11:364-70. doi: 10.1038/nrcardio.2014.37

53. Maheu-Cadotte MA, Pepin C, Lavallee A, Hupe C, Mailhot T, Duchaine $\mathrm{C}$, et al. CE: gestational hypertension, preeclampsia, and peripartum cardiomyopathy: a clinical review. Am J Nurs. (2019) 119:32-40. doi: 10.1097/01.NAJ.0000605352.84144.a2

54. Kumar S, Baldinger SH, Gandjbakhch E, Maury P, Sellal JM, Androulakis $\mathrm{AF}$, et al. Long-Term arrhythmic and nonarrhythmic outcomes of lamin A/C mutation carriers. J Am Coll Cardiol. (2016) 68:2299-307. doi: 10.1016/j.jacc.2016.08.058

55. Ware JS, Li J, Mazaika E, Yasso CM, DeSouza T, Cappola TP, et al. Shared genetic predisposition in peripartum and dilated cardiomyopathies. N Engl J Med. (2016) 374:233-41. doi: 10.1056/NEJMoa15 05517
56. Toescu V, Nuttall SL, Martin U, Kendall MJ, Dunne F. Oxidative stress and normal pregnancy. Clin Endocrinol (Oxf). (2002) 57:609-13. doi: $10.1046 / j .1365-2265.2002 .01638 . x$

57. Ricke-Hoch M, Pfeffer TJ, Hilfiker-Kleiner D. Peripartum cardiomyopathy: basic mechanisms and hope for new therapies. Cardiovasc Res. (2019) 116:520-31. doi: 10.1093/cvr/cvz252

58. Brundel BJ, Shiroshita-Takeshita A, Qi X, Yeh YH, Chartier D, van Gelder IC, et al. Induction of heat shock response protects the heart against atrial fibrillation. Circ Res. (2006) 99:1394-402. doi: 10.1161/01.RES.0000252323.83137.fe

59. van Marion DMS, Dorsch L, Hoogstra-Berends F, Kakuchaya T, Bockeria L, de Groot NMS, et al. Oral geranylgeranylacetone treatment increases heat shock protein expression in human atrial tissue. Heart Rhythm. (2020) 17:115-22. doi: 10.1016/j.hrthm.2019.07.010

60. van Marion DM, Hu X, Zhang D, Hoogstra-Berends F, Seerden JG, Loen L, et al. Screening of novel HSP-inducing compounds to conserve cardiomyocyte function in experimental atrial fibrillation. Drug Des Devel Ther. (2019) 13:345-64. doi: 10.2147/DDDT.S176924

61. Levi V, Jacobson EL, Jacobson MK. Inhibition of poly(ADP-ribose) polymerase by methylated xanthines and cytokinins. FEBS Lett. (1978) 88:144-6. doi: 10.1016/0014-5793(78)80627-9

62. Robson M, Im SA, Senkus E, Xu B, Domchek SM, Masuda N, et al. Olaparib for metastatic breast cancer in patients with a germline BRCA mutation. $N$ Engl J Med. (2017) 377:523-33. doi: 10.1056/NEJMoa1706450

63. Swaisland H, Plummer R, So K, Garnett S, Bannister W, Fabre MA, et al. Olaparib does not cause clinically relevant QT/QTc interval prolongation in patients with advanced solid tumours: results from two phase I studies. Cancer Chemother Pharmacol. (2016) 78:775-84. doi: 10.1007/s00280-016-3124-5

64. Neubauer S. The failing heart-an engine out of fuel. N Engl J Med. (2007) 356:1140-51. doi: 10.1056/NEJMra063052

65. Pillai VB, Sundaresan NR, Kim G, Gupta M, Rajamohan SB, Pillai JB, et al. Exogenous NAD blocks cardiac hypertrophic response via activation of the SIRT3-LKB1-AMP-activated kinase pathway. J Biol Chem. (2010) 285:313344. doi: 10.1074/jbc.M109.077271

66. Airhart SE, Shireman LM, Risler LJ, Anderson GD, Nagana Gowda GA, Raftery D, et al. An open-label, non-randomized study of the pharmacokinetics of the nutritional supplement nicotinamide riboside (NR) and its effects on blood NAD ${ }^{+}$levels in healthy volunteers. PLoS ONE. (2017) 12:e0186459. doi: 10.1371/journal.pone.0186459

67. Brundel BJ, Henning RH, Ke L, van Gelder IC, Crijns HJ, Kampinga HH. Heat shock protein upregulation protects against pacing-induced myolysis in HL1 atrial myocytes and in human atrial fibrillation. J Mol Cell Cardiol. (2006) 41:555-62. doi: 10.1016/j.yjmcc.2006.06.068

68. Sakabe M, Shiroshita-Takeshita A, Maguy A, Brundel BJ, Fujiki A, Inoue $\mathrm{H}$, et al. Effects of a heat shock protein inducer on the atrial fibrillation substrate caused by acute atrial ischaemia. Cardiovasc Res. (2008) 78:63-70. doi: $10.1093 / \mathrm{cvr} / \mathrm{cvn} 019$

Conflict of Interest: The authors declare that the research was conducted in the absence of any commercial or financial relationships that could be construed as a potential conflict of interest.

Copyright $\odot 2020$ Ramos and Brundel. This is an open-access article distributed under the terms of the Creative Commons Attribution License (CC BY). The use, distribution or reproduction in other forums is permitted, provided the original author(s) and the copyright owner(s) are credited and that the original publication in this journal is cited, in accordance with accepted academic practice. No use, distribution or reproduction is permitted which does not comply with these terms. 